\title{
Protokole Dayalı Tedavinin Ağır Sepsis Mortalitesi Üzerine Etkisi
}

\section{The Effect of Protocol Guided Therapy to Severe Sepsis Mortality}

\author{
Elif Çopuroğlu, Yalım Dikmen*, Oktay Demirkıran*, Tuğhan Utku*, Seval Ürkmez* \\ Trakya Üniversitesi Tıp Fakültesi, Anesteziyoloji ve Reanimasyon Anabilim Dalı, Edirne, Türkiye \\ *Istanbul Üniversitesi Cerrahpaşa Tıp Fakültesi, Anesteziyoloji ve Reanimasyon Anabilim Dalı, Istanbul, Türkiye
}

\section{ÖZET}

Amaç: Protokole dayalı tedavinin ağır sepsis mortalitesi üzerine etkisi ve bu protokole uyumun incelenmesi amaçlandı.

Hastalar ve Yöntem: Ağır sepsis ve septik şok hastalarının tedavilerine yol göstermek amacı ile kanıta dayalı sepsis tedavi rehberine dayanılarak 'Ağır Sepsis Tedavi Protokolü' geliştirildi. Çalışmaya başlamadan önce tüm yoğun bakım çalışanlarına sepsisin tanı kriterleri ve ağır sepsis tedavi protokolü hakkında (Ek 1) bilgi verildi. Yoğun Bakım Ünitesinde 2003-2004 yıllar arasında tedavi gören 148 ağır sepsis ve septik şok hastası geriye dönük olarak yaş, APACE II ve SOFA skorları, infeksiyon odağı ve organ yetersizlikleri ve mortalite açısından incelendi. Bu hastalar retrospektif çalışma grubumuzu (RG) oluşturdu. Prospektif grup (PG) ise, Haziran 2005- Haziran 2006 tarihleri arasında aynı yoğun bakım ünitesinde, Ağır Sepsis Tedavi Protokolü uygulanarak tedavi gören 62 ağır sepsis ve septik şok hastalarından oluşturuldu. Protokole dayalı tedavi uygulanan PG grubunda gözlemlenen mortalite oranı, RG grubu ile karşılaştııılı. PG grubunda ilk 6 saatlik ve 24 saatlik tedavi demetlerindeki protokole uyum incelendi.

Bulgular: Prospektif grupta mortalite oranı daha düşüktü; fakat bu fark istatistiksel olarak anlamlı saptanmadı. Illk 6 saatlik tedavi demetinde protokole uyum ortalama \%84,4, 24 saatlik tedavi demetinde ise $\% 59,5$ olarak bulundu.

Sonuç: Protokole dayalı tedavinin, ağır sepsis ve septik şok hastalarında, ölüm oranını düşürdüğü kanaatindeyiz. (Türk Yoğun Bakım Derneği Dergisi 2011; 9: 90-8)

Anahtar Kelimeler: Sepsis, protokol, mortalite

\section{SUMMARY}

Aim: The aim of our study was to investigate the effect of protocolbased therapy to the severe sepsis patients and to investigate the accordance with this protocol.

Patients and Methods: According to the evidence based guideline therapy, 'Severe Sepsis Treatment Protocol' was evaluated in order to lead the therapy of severe sepsis and septic shock patients. Before starting to our study, all the intensive care stuffs were informed about the diagnostic criteria for sepsis and severe sepsis (Appendix 1). One hundred and forty eight severe sepsis and septic shock patients that underwent therapy between 2003-2004 at Sadi Sun Intensive Care Unit were investigated retrospectively to create our Retrospective Group (RG). The study group was performed on 62 severe sepsis patients, that had underwent 'Severe Sepsis Treatment Protocol' based therapy at the same intensive care unit, between June 2005- June 2006 named as Prospective Group (PG). The mortality rate was compared between two groups. The treatment compliances at the first 6 hours and 24 hours has been evaluated in group PG.

Results: Mortality rate was lower in PG, but this difference was not statistically significant $(p>0.204)$. The accordance to the protocol of the first 6 hour therapy bundle and the 24 hour therapy bundle was found \%84.46 and \%59.54 respectively.

Conclusion: Our study shows that, protocol-based therapy decreases the mortality in severe sepsis and septic shock patients. (Journal of the Turkish Society Intensive Care 2011; 9: 90-8) Key Words: Sepsis, protocol, mortality

Yazışma Adresi/Address for Correspondence: Dr. Elif Çopuroğlu, Trakya Üniversitesi Tıp Fakültesi, Anesteziyoloji ve Reanimasyon Anabilim Dalı, Edirne, Türkiye Tel.: +90 2842357641 E-posta: elifcopuroglu@hotmail.com Geliş Tarihi/Received: 10.11.2011 Kabul Tarihi/Accepted: 14.12.2011 


\section{Giriş}

Sepsis tanımlanması, tanı konulması ve tedavisi oldukça zor, buna karşın sık karşısşılan ve yaşamı tehdit eden önemli bir sağlık sorunudur (1). Sepsisin yıllık görülme sıklığı 100.000 'de 50-95 olgudur ve bu sıklık her yıl \%9 oranında artış göstermektedir (2). Bu hastalık tüm hastane yatışlarının $\% 2^{\prime}$ sini oluşturur (3).

Sepsis, koroner bakım dışındaki yoğun bakım ünitelerinde (YBÜ) rastlanılan ölümlerin en önemli nedenidir (4). Uluslararası literatürde ağır sepsis mortalitesi \%30-50 arasında bulunmaktadır (5). Ülkemizde sepsis mortalitesi üzerine yapılan geniş kapsamlı çalışmalar bulunmasa da, yapılan sepsis araştırmalarında bildirilen mortalite oranları bu sayıların oldukça üzerinde seyretmektedir $(6,7)$.

Uzun yıllardır ağır sepsis ile ilgili yapılan özverili, yüksek maliyetli fakat bir o kadar da hekimleri hayal kııklığına uğratıcı çalışmaların ardından, çeşitli merkezlerden mortaliteyi azaltmak ile ilgili olumlu sonuçlar bildirilmeye başlamıştır. Erken Hedefe Yönelik Tedavi (EGDT) (8), drotrekogin alfa (9), düşük doz steroid tedavisi (10), sıkı kan şekeri kontrolü (11), düşük tidal volüm ventilasyonu (12) ve sepsisin erken tanısında tanı kriterleri demetlerinin kullanılması (13) mortaliteyi düşürmeye yönelik yapılan randomize kontrollü çalışmalardır.

Çalışmamızda, ağır sepsis tedavi protokolünün uygulanması ile sepsise bağlı mortalitenin, protokol uygulanmayan dönemde aynı yoğun bakım ünitesinde tedavi gören ağır sepsis hastalarına göre değişimini görmeyi amaçladık.

\section{Gereç ve Yöntem}

Bu çalışma, Etik Kurul onayı alındıktan sonra (07 Haziran 2005 tarih, 14613 sayı) Haziran 2005-Haziran 2006 tarihleri arasında yoğun bakım ünitemizde yatan ağır sepsis hastaları dahil edilerek yapılımışır.

Çalışma; YBÜ'nde tedavi gören ağır sepsis hastaları ile ilişkili müdahalesiz, tarihsel kontrollü, prospektif ve gözlemsel bir çalışmadır. Çalışmamızda ağır sepsis tanısı ACCP/SCCM uzlaşı tanımlarına göre belirlendi (Ek 1). Yoğun bakım ünitesine ağır sepsis tanısı ile bir defadan fazla yatan hastalar, her yatışlarında tekrar değerlendirildi. Yoğun bakım ünitemize başka bir yoğun bakım ünitesinden ağır sepsis tanısı ile sevk edilen hastalar çalışma dışı bırakıldı.

Yoğun Bakım Ünitesinde ağır sepsis ve septik şok hastalarının tedavilerine yol göstermek amacı ile kanıta dayalı sepsis tedavi rehberine dayanılarak 'Ağır Sepsis Tedavi Protokolü' geliştirildi (Ek 1).

Çalışmamıza başlarken aynı YBÜ'nde 2003-2004 yılları arasında tedavi gören 148 ağır sepsis ve septik şok hastasının verileri retrospektif olarak incelendi. Bu hastalar Retrospektif Grubumuzu (RG) oluşturdu.
Retrospektif olarak toplanan verilerin içeriği: Hastanın demografik özellikleri, ilişkili eşlik eden durumlar, hastalık tanı kriterleri, hastalığın ağırlığı ile ilgili ölçütler, birincil enfeksiyon bölgesi, sepsis odağı, başvurudaki organ yetersizliklerinin sayısı, YBÜ'nde uygulanan tedavi biçimleri ve sağkalımları değerlendirildi.

Prospektif çalışma grubumuzu (PG), 2005-2006 tarihleri arasında aynı YBÜ'nde protokole dayalı tedavi gören hastalar oluşturdu. Çalışmaya başlamadan önce tüm yoğun bakım çalışanlarına ACCM/SCCM uzlaşısına göre sepsisin tanı kriterleri ve ağır sepsis tedavi protokolü hakkında (Ek 1) bilgi verildi. Daha sonra kliniğimizde çalışan tüm hekimlere konu ile ilgili seminer verildi. Katılımcıların hepsine ağır sepsis tedavi protokolü (Ek 1) fotokopi olarak sunuldu. Protokol, YBÜ sorumlu doktorları ve asistan doktorlar ile tekrar tartışıldı. Bu toplantıda katılımcılara protokole uyumu takip etmede kullanılacak olan Ağır Sepsis Takip Formu (Ek 2) anlatıldı. Ağır sepsis tedavi protokolü (Ek 1) YBÜ'nde kolay ulaşılabilecek şekilde bırakıldı. Tüm hasta başı klasörlerine sepsis, ağır sepsis ve septik şok tanısını içeren şablonlar yerleştirildi. Ağır Sepsis Takip Formu'nun (Ek 2) ünitemizde tedavi gören tüm sepsis hastaları için özenle doldurulması sağlandı.

Prospektif dönemde yatan tüm hastaların demografik bilgileri, hastalık ağırığı ile ilgili bilgiler (APACHE II ve SOFA), sepsis odağı, başvurudaki organ yetersizliklerinin sayısı ve sağkalımları kaydedildi.

Protokole uyum, çalışma grubundaki her hasta için kaydedilen formlarda yer alan girişimlerden, uygulanması beklenenlerin sayısı ile uygulananların sayısının oranları hesaplanarak kontrol edildi. Bu girişimler aşağıda sıralanmıştır:

İlk 6 saatlik tedavi demetinde: Laktat düzeyinin bakılması, antibiyotik tedavisi başlanmadan önce hemokültür alınması, acil servisten kabul edilen hastalarda 2, diğer servislerden gelen hastalarda 1 saat içinde geniş spektrumlu antibiyotik başlanması,

Ağır sepsise bağılı perfüzyon yetersizliği olan hastalarda: Sıvı replasmanı yapılması, vazopresör başlanması, $\mathrm{ScVO}_{2}$ düşük olanlarda dobutamin başlanması, eritrosit transfüzyonu yapılması, vazopresör uygulanan hastalarda düşük doz steroid başlanması.

24 saatlik tedavi demetinde; APACHE II'si 25'in üstünde olanlarda drotrecogin alfa başlanması, ortanca kan şekeri düzeyinin $150 \mathrm{mg} / \mathrm{dL}$ 'nin altına düşürülmesi, ortanca havayolu basıncının $30 \mathrm{cmH}_{2} \mathrm{O}^{\prime}$ nun altında olması.

\section{İstatistiksel Değerlendirme}

Çalışmanın birincil hedefine yönelik olarak RG grubu ile PG grubu arasındaki mortalite farkının incelenebilmesi için $\chi^{2}$ testi kullanıldı. Veriler parametrik değerler için ortalama \pm standart sapma-SD (\%95 güvenillik aralığı) olarak, nonparametrik değerler ise ortanca (minimum-maksimum) olarak sunuldu, tüm testlerde $p<0,05$ anlamlı olarak kabul edildi. 


\section{Bulgular}

Her 2 grup demografik verileri (yaş ortalaması, cinsiyet dağılımları), organ yetersizlikleri açısından karşılaştıııldı. Demografik veriler açısından gruplar arasında istatistiksel olarak anlamlı fark saptanmadı. Her iki grupta hastalığın ağırlığı APACHE II ve giriş SOFA değerleri ile belirlenmiştir. Iki grubun ciddiyet skorları karşılaştıııldığında istatistiksel olarak benzer bulunmuştur (APACHE $\| p=0,731$, SOFA $p=0,201$ ) (Tablo 1). RG'ta 148, PG'ta 62 ağır sepsis ve septik şok hastası bulunmaktadır. Her iki grup sepsis odağına göre incelendiğinde PG'taki hastaların $9(\% 14,5)^{\prime} u$ akciğer, 31 $(\% 50)^{\prime} \mathrm{i}$ intraabdominal, $6(\% 9,7)$ 'sı üriner, 16 (\%25,8)'sı diğer kaynaklı, RG'taki hastaların $58(\% 39,2)$ 'i akciğer, 57 $(\% 38,5)$ 'si intraabdominal, $11(\% 7,4)^{\prime} i$ üriner, 22 (\%14,9)'si diğer kaynaklı, olduğu görülmüştür (Tablo 2).

Tablo 1. İki grubun karşılaştırılması (demografik veriler, organ yetersizlikleri sayısı ve ciddiyet skorlarının karşılaştııılması)

\begin{tabular}{lcc} 
& $\begin{array}{c}\text { Retrospektif } \\
\text { Grup (n=148) }\end{array}$ & $\begin{array}{c}\text { Prospektif } \\
\text { Grup (n=62) }\end{array}$ \\
\hline Yaş & $55,32 \pm 20,28$ & $59,02 \pm 18,17$ \\
Cinsiyet (K/E) & $58 / 90$ & $22 / 40$ \\
Organ yetersizliklerinin sayısı & $4(2-5)$ & $4(2-6)$ \\
APACHE II & $23,8 \pm 8,9$ & $24,8 \pm 7,4$ \\
SOFA & $9,0 \pm 4,2$ & $7,8 \pm 3,6$ \\
\hline
\end{tabular}

Tablo 2. íki gruptaki olguların infeksiyon odağına göre karşılaştırılması

Retrospektif Prospektif Grup ( $n=148) \quad$ Grup ( $=62)$

\begin{tabular}{lcc}
\hline Akciğer & 58 & 9 \\
Intraabdominal & 57 & 31 \\
Üriner & 11 & 6 \\
Diğer & 22 & 16
\end{tabular}

Tablo 3. Retrospektif grupta organ yetersizliklerinin sayısına göre mortalite dağılımı

\begin{tabular}{ccccc} 
& 1 Organ & 2 Organ & 3 Organ & $>$ 4 Organ \\
\hline Mortalite (\%) & 33 & 41,2 & 63,5 & 87,7
\end{tabular}

Tablo 4. Klinik sonuç

\begin{tabular}{lcc} 
& $\begin{array}{c}\text { Retrospektif } \\
\text { Grup (n=148) }\end{array}$ & $\begin{array}{c}\text { Prospektif } \\
\text { Grup (n=62) }\end{array}$ \\
\hline Şifa \% (n) & $35,8(53)$ & $45,2(28)$ \\
Ölüm \% (n) & $64,2(95)$ & $54,8(34)$ \\
\hline
\end{tabular}

RG'ta mortalite ile organ yetersizlikleri arasında belirgin bir ilişki saptanmıştır. Organ yetersizliklerinin sayısına göre mortalite dağılımı Tablo 3'te gösterilmiştir.

Hastaların sonuçları yoğun bakım ünitesinden taburcu olmaları şifa ya da ölüm olarak değerlendirilmiştir. RG'ta ölüm oranı \%64,2 iken, PG'ta bu oran \% 54,8 olarak saptanmıştır. Protokole dayalı tedavi ile hastaların tedavi gördüğü PG'taki mortalitedeki düşüş istatistiksel olarak anlamlı bulunmamıştır ( $p=0,204)$ (Tablo 4).

Protokole uyum incelendiğinde; Illk 6 saatlik tedavi demetinde: Laktat düzeyinin bakılması \%98,4, antibiyotik tedavisi başlanmadan önce hemokültür alınması \%98,4, acil servisten kabul edilen hastalarda 2, diğer servislerden gelen hastalarda 1 saat içinde geniş spektrumlu antibiyotik başlanması \%73,0 oranında gerçekleşmiştir;

Ağır sepsise bağlı perfüzyon yetersizliği olan hastalarda: Sıvı replasmanı yapılması \%96,4, Vazopresör başlanması \%93,7, ScVO2 düşük olanlarda dobutamin başlanması $\% 50,0$, eritrosit transfüzyonu yapılması \%83,3, vazopresör uygulanan hastalarda düşük doz steroid başlanması \%82,3 oranında gerçekleşmiştir. Ilk 6 saat tedavi demetine ortalama uyum $\% 84,5^{\prime}$ tir.

24 saatlik tedavi demetlerinde; APACHE II'si 25'in üstünde olanlarda drotrekogin alfa başlanması \%12,5, ortanca kan şekeri düzeyinin 150 mg/dL'nin altına düşürülmesi \%66,1, ortanca havayolu basıncının $30 \mathrm{cmH}_{2} \mathrm{O}$ 'nun altında olması \%100, 24 saatlik tedavi demetlerine ortalama uyum \%59, $5^{\prime}$ tir.

\section{Tartışma}

Çalışmamızın sonucunda ağır sepsis ve septik şok tedavisinde protokol bazlı yaklaşıma ilk 6 saatte \%84,5, ilk 24 saatlik periyotta ise \%59,5 oranında katııı sağlanmış ve hasta mortalitesinde istatistiksel olarak anlamlı olmasa da \%10 gibi bir düşüş görülmüştür.

Brun-Buisson'un, sepsisin görülme sıklığı ve ölüm oranı ile ilgili yayınlanmış çalışmalardan yapılan derlemesinde (14), hastaneye başvuran 1000 hastanın 45'inde, yoğun bakıma başvuran 1000 hastanın 494'ünde sepsis geliştiği belirtilmektedir. Bizim çalışmamızda retrospektif grubumuzu oluşturan 148 ağır sepsis ve septik şok hastası o yı içinde toplam yoğun bakıma yatan hastalarımızın \%8,3'ünü oluşturmakta iken, prospektif grubumuzu oluşturan ağır sepsis ve septik şok hastaları o yıl içindeki toplam yoğun bakıma yatan hastalarımızın \%5,0'ini oluşturmaktaydı. Sepsisin tanı ve tedavilerini anlatan seminerlerimizin de etkisi ile sepsis hastalarının daha erken tanınması ve tedavi edilmesi sağlanarak ağır sepsis ve septik şok hastalarının görülme sıklığında düşüş sağlandığı kanaatindeyiz.

Tüm dünyada her gün 1400 hastanın sepsis nedeniyle hayatını kaybettiği bildirilmektedir (15). Sepsisli hastalarda en sık ölüm nedenlerini septik şok ve çoklu organ yetersizliği oluşturmaktadır $(16,17)$. Sepsisli hastalarda mortalite \%30'larda (9) iken, ağır sepsis ve septik şoklu hastalarda bu 
oran \%40-70'lere kadar yükselmektedir (18). Çalışmamızda protokole dayalı tedavi uygulayarak ağır sepsis ve septik şok hastalarındaki \%64,2 olan mortalite oranımızın, \%54,8'e düşmesini sağladık. Aynı zamanda bu çalışma sayesinde sepsisin erken tanınıp hastalı̆ın ağır sepsis ve septik şoka ilerlemesinde gecikme hatta engellenme sağlanarak ağır sepsis ve septik şok hastalarının tüm yoğun bakım hastane yatışımızdaki oranını düşürerek dolaylı olarak mortalitede de düşüş yaşanmıştır.

Sepsisin tanı ve tedavisinde, patofizyolojisindeki bilgilerin geliştirilmesi kadar, tüm klinisyenlerin sepsisin erken teşhisi ve tedavisi hakkında bilgilendirilmeleri de önemlidir. Nitekim yoğun bakım sorumlu hekimlerinin bu konuda bilgilendirilmeleriyle sepsisli hastaların yaşama şanslarının artışının ilişkili olduğu gösterilmiştir (19). Poeze ve arkadaşlarının (20) Avrupa ve Amerika'dan randomize olarak seçtikleri 1058 yoğun bakım klinisyenine telefonla sepsis hakkında sorular yönelterek yaptıkları çalışmanın sonucunda, klinisyenlerin çoğunun sepsisin yayınlanmış uzlaşı tanı kriterlerini tanımlayamadıkları ve sepsisin yoğun bakım ölümlerinin önde giden sebeplerinden olmaya devam ettiği belirtilmiştir. Eğitim ve seminerler vererek sepsisin erken tanı ve tedavisinde başarı elde etmemize rağmen, oluşturduğumuz tedavi protokolüne uyumumuzda ilk 6 saatte yüksek uyum oranı sağlanmasına karşın, 24 saatlik tedavide uyum daha düşük olarak bulunmuştur. Sepsis gibi birçok organı etkileyerek teşhis ve tedavi çeşitiliklerinin çok faktöre dayandığı multisistemik hastalıklarda tedavide yer alan ekibin sık aralıklarla bilgilendirilerek, oluşturulan protokollere uyumun daha yakından takip edilmesi, hatta ekibin kendi kendini test edebileceği tedavi işaret şemaları oluşturulması da faydalı olabilir.

Klinikte erken ve etkin tedavinin önemini vurgulayan, 'altın saatler' terimini tanımlayan ve kullanan çalışmalar ön plana çıkmaktadır. Travmaya bağı hipovolemik şokta (21), miyokard infarktüsüne bağlı kardiyojenik şokta (22), masif pulmoner embolizme bağlı obstrüktif şokta (23), Rivers ve arkadaşlarının erken hedefe yönelik tedavinin önemini belirttikleri sepsis çalışmasında (8), hep 'altın saatler'deki tedavilerin mortaliteyi azaltması üzerinde durulmaktadır. Bizim çalışmamızda da protokole uyumumuzu incelediğimizde özellikle ilk 6 saatteki uyum oranımı oldukça yüksekti. Biz de çalışmamızın sonucunda protokole dayalı tedavi uygulaması ile mortalite oranında sağlamış olduğumuz düşüşteki en önemli faktörün ilk 6 saatteki etkin tedavi başarımıza bağlı olduğu kanaatindeyiz.

Klinik rehberlere dayalı tedavi tüm sağlık çalışanları için son yılların ilgi çekici konuları arasında gelmektedir. Çalışma grubumuzda uyguladığımı Ağır Sepsis Tedavi Protokolümüzü oluştururken literatürde farklı klinik problemler ile ilgili rehberler, tedavi demetleri ve bunların kliniğe uygulanmalarını içeren birçok bilgiye rastladık.

Klinik rehberlerin, 'Institute of Medicine' tarafindan yapılan tanımlamasına göre bu rehberler, klinisyenlerin uygun hasta başı tedavilerini ve özel klinik durumlarındaki kararlarını vermede yardımcı olmak için sistematik olarak düzenlenmiş bildirilerdir. Klinik rehberlerin kullanımı hasta tedavilerinin gelişimi için iyi bir seçenektir $(24,25)$. Klinik rehberlerin hastalara uygunsuzluğu bu rehberleri hazırlayan ilgili kişilerce en aza indirilmeye çalışılsa da; bu rehberlere dayalı tedavilerdeki rehberlere uyumlardaki gecikmeler, bir diğer önemli sorundur (26). Özellikle sepsis gibi yüksek mortalite ile seyreden ve çok çeşitli klinik tablo ile karşımıza çıkan hastalık durumlarında tüm hastalık seyrindeki çeşitliliğin iyi analiz edilmesi klinisyenlerin kararsızlıklarını azaltmada faydalı olacaktır (27).

Trzeciak ve arkadaşları (28) New Jersey'de bir üniversite hastanesinde bir yıl boyunca acil servis ve yoğun bakımlarında erken hedefe yönelik tedavi gören 22 septik şok hastasından oluşan hasta grubunu retrospektif olarak incelemişler; bu grubu yine aynı hastanede daha önceki yıllarda standart tedavi uygulanan septik şok hastaları ile karşılaşıırdıklarında toplam hastanede yatış sürelerini 4 gün daha kısa olduğunu ve ölüm oranlarının istatistiksel olarak anlamlı olmasa da \%25,6 daha düşük olduğunu saptamışlardır. Micek ve arkadaşlarının standardize hastane rehberine göre tedavi ettikleri 60 septik şok hastasının, 60 hastalık tarihsel kontrol grubu ile karşılaştııılığı çalışmalarında; acil serviste rehbere dayalı olarak tedavileri başlanan grupta, daha fazla sıvı tedavisi, daha erken antibiyoterapiye başlama ve daha az vazopresör kullanımı sağlandığını saptamışlardır. Yine bu grupta kontrol grubuna göre \%18 daha düşük mutlak ölüm oranı bildirmişlerdir (29). Biz de protokole dayalı tedavi uyguladığımız ağır sepsis ve septik şok hastalarında ölüm oranında uygulanmayan retrospektif grubumuza göre \%10 düşüş saptadık.

Ağır sepsis ve septik şokta rehberlere dayalı tedavi uygulanan literatürlerde (28,30-33), protokollere uyumdan çok bahsedilmemektedir. Çalışmamızda protokole uyumda oldukça yüksek oranlar elde ettik. Çalışmamıza baktığımızda da protokolün uygulanmaya başlamasıyla ağır sepsis olgularında bu derece ciddi bir düşüş görülmesi bile başlı başına çok önemli bir sonuçtur. Protokole uyumda en çok yaşanan aksaklık antibiyotik kullanımındaki gecikme oldu. Bu gecikmeye acil servisin kalabalık ortamında yaşanan karışıklıklar; acilde ve diğer servislerde hekimlerimizin sepsisin tanı kriterlerini gözden kaçırmaları ve antibiyoterapiye geç başlanması; yoğun bakım ünitesi dahil hastanemizde tedavi edilen hastaların bir bölümünün sağlık sigortalarının bile olmaması veya bulunan sağlık sigortalarının akademik hastane olan hastanemizde tüm ilaç ücretini karşılamamasının neden olduğu ileri sürülebilir. Yapılan çalışmalar antibiyoterapiye başlamadaki gecikmelerin hastane mortalitesini arttırdığını göstermektedir $(26,34,35)$.

Literatürde sepsiste protokole dayalı tedavi ile yapılan çalışmaları incelediğimizde $(13,33,36)$ oluşturulan protokole uyumları bildiren üç çalışmaya rastlamaktayız. Gao ve 
arkadaşlarının (33) yaptıkları prospektif çalışmada, ilk 6 saatlik tedavi demetine uyum \%52, 24 saatlik tedavi demetine uyum \%30 olarak bildirilmiştir. Bir diğer çalışma 2007 yllında Amerika'da yapılan çalışmadır. Bu çalışmada başlangıçtaki tedavi demetine uyum sifir iken iki yilın sonunda \%51'e yükselmiştir (13). Surviving Sepsis Campaign Update ekibinin 2005-2008 tarihleri arasında 165 merkezde protokole dayalı tedavi uygulanan 15022 hastadan elde ettikleri verileri analiz ederek yaptıkları değerlendirmede protokole ortalama uyumun $\% 18,4$ 'ten $\% 36,1$ 'e yükseldiğini, hastane mortalitesinin ise $\% 37,2^{\prime}$ den \%30,8'e düştüğünü göstermişlerdir (36). Bizim çalışmamızda protokole uyum oldukça yüksektir. Illk 6 saatlik tedavi demetine ortalama uyum $\% 84,46 ; 24$ saatlik tedavi demetine ortalama uyum \%59,54'dür. Yukarıdaki çalışmalar $(13,33,36)$ genel olarak daha az sayıda hastayı kapsayan çalışmalar olduğundan mortalite azalması yönünde bulgular istatiksel anlamlılığa ulaşmamış olabilir. Çalışmamızdaki protokole uyum oranlarının yüksek olmasını ise protokol kullanıma başlamadan önce gerek seminerler ile açıklanıp gerekse yoğun bakım ünitelerinde kolay ulaşılabilen bilgilendirilme kartlarının hazırlanıp sunulması ve protokolümüzün pratik uygulanabilirliği, kolay anlaşılabilirliği nedenlerinden olduğunu düşünmekteyiz.

Miguel-Yones ve arkadaşları (37) üniversite hastanesinin acil servisinde protokole dayalı tedavi uyguladıkları çalışmalarında, tedavi ettikleri 53 sepsis hastasının 23'ünde organ yetersizliğinin olmadığını, 15'nde 1 organ, 9'unda 2 organ ve 6'sında 3 organ yetersizliği bulunduğunu belirtmişlerdir. Bu hastaların hiçbirinde 4 veya 5 organ yetersizliği olmadığını belirtmişlerdir.
Bizim çalışma grubumuzdaki hastalar genel olarak çoklu organ yetersizliği gelişmiş ve mortalite riski çok yüksek olan hastalardır. Bu nedenle hem kontrol grubu (tarihsel grup) hem de çalışma grubunda görülen mortalite oranları literatürde bildirilen oranların çok üzerindedir. Bu sorun bize sepsis tedavisi ile ilgili protokollerin yalnızca sepsis tedavisi ile sınırlı kalmaması gerektiğini; bunun yanında hastanenin servislerinde yatarken sepsis gelişen hastaların erken dönemde tanınmasını ve tedavisinin başlanmasını sağlayacak araçların da geliştirilmesi gerektiğini göstermektedir.

Çalışmamızın eleştiriye açık bir yanı kontrol grubumuzu hastaları retrospektif inceleyerek oluşturmuş olmamız ve bu grupta uygulanan tedavilerin standartlaştıılması ve karşılaştııımasındaki zorluktur. Ancak klinik düzeyde kabul gören bir tedavi rehberi oluşturulduktan sonra bu rehberin dışında uygulamalar yapılması mümkün olmadığından eş zamanlı bir kontrol grubu oluşturmak etik olarak olanaksızdır. Yine de kontrol grubundaki hastaların da aynı yoğun bakım şartlarında, aynı klinisyen ekiple tedavilerinin sağlanması, tarihsel kontrollü karşılaştırma yapılan çalışmalarla karşılaştııılı̆̆ında avantaj olarak belirtilebilir.

\section{Sonuç}

Çalışmamızda, klinik olarak çok önemli ve neden olduğu mortalite riski açısından etkin tedavi uygulamasının yaşamsal önem taşıdığı ağır sepsis olgularında tedavi rehberinin ve buna uygun tedavi uygulamasının mortalitenin azaltılmasında etkili olabileceği sonucuna varılıışır.

\section{EK 1 Ağır Sepsis Tedavi Protokolü:}

Ağır sepsis tanısının zamanında konması ve aşağıda sayılan tedavilerin hızla başlanması sepsis mortalitesinin azaltılması için şarttır. Aşağıda maddeler halinde yazılan işlemlerin hepsi bir arada ve etkin bir şekilde uygulanmalıdır. Maddeler halinde yazımasının sebebi öncelik sıralaması değildir.

1. Ağır Sepsis tanısı ACCP/SCCM uzlaşı tanımlarına göre konur. Sepsis tarama formuna bakın

1.1. SIRS kriterleri

1.1.1. Ateş $>38,3^{\circ} \mathrm{C}$ (veya $>38,0 \stackrel{\circ}{ }$ cilt Isısı) veya $<36,0 \circ \mathrm{C}$

1.1.2. Nabız $>90 / d k$

1.1.3. Solunum frekansı $>20 / d k$

1.1.4. Lökosit sayısı $>12,000 / \mathrm{mm}^{3}$ veya $<4,000 / \mathrm{mm}^{3}$ veya lökosit formülünde >\%10 immatür nötrofil

1.2. Infeksiyon varlığı veya şüphesi (titreme, ürperme veya ense sertliği ve baş ağrısı vb)

1.3. Organ fonksiyon bozukluğu

1.3.1. Sistolik arter basıncı $<90 \mathrm{mmHg}$ veya 40 mmHg'dan fazla ani düşüş veya ortalama arter basıncı <65 $\mathrm{mmHg}$ ve/veya laktat $>4 \mathrm{mmol} / \mathrm{L}$.
1.3.2. $\mathrm{PaO}_{2}<70 \mathrm{mmHg}$ veya $\mathrm{O} 2$ satürasyonu $<\% 90$ veya $\mathrm{PaO}_{2} / \mathrm{FiO}_{2}<300$

1.3.3. İrar çıkışı $<0,5 \mathrm{~mL} / \mathrm{kg} /$ saat ve/veya kreatinin $>2$ $\mathrm{mg} / \mathrm{dL}$

1.3.4. Trombosit sayısı $<100,000 / \mathrm{mm}^{3}$

1.3.5. Total bilirübin düzeyi $>2 \mathrm{mg} / \mathrm{dL}$

1.3.6. Koagülasyon testlerinde INR $>1,5$ veya APTT $>60$ sn

1.3.7. Ani gelişen şuur değişiklikleri (konfüzyon, psikoz, stupor, koma

1.3.8. Kan gazında metabolik asidoz $\left(\mathrm{pH}<7,35\right.$ ve $\mathrm{HCO}_{3}$ $<22 \mathrm{mEq} / \mathrm{L})$

2. Ağır sepsis tanısı konan hastada yapılacak işlemler:

2.1. Kan gazı analizi yapılacak

2.1.1. Maske ile oksijen

2.1.2. Endikasyonu varsa noninvazif ventilasyon veya intübasyon ve mekanik ventilasyon (SSYB protokollerine göre)

2.2. Arter kanülü ve santral ven kateterizasyonu yapılacak. Sistolik arter basıncı $<90 \mathrm{mmHg}$ veya 40 mmHg'dan fazla ani düşüş veya ortalama arter basıncı <65 $\mathrm{mmHg}$ ve/veya Laktat $>4 \mathrm{mmol} / \mathrm{L}$ ise 
2.2.1. Intravenöz SIVI $\geq 20 \mathrm{~mL} / \mathrm{kg}$ Laktatlı Ringer veya $\% 0,9 \mathrm{NaCl}$ veya $5 \mathrm{~mL} / \mathrm{kg}$ Voluven 30 dakikada gidecek şekilde verilecek.

2.2.1.1. Bu uygulamaya $S A B>90 \mathrm{mmHg}$ veya $O A B>65$ oluncaya veya santral ven basıncı $15 \mathrm{mmHg}$ 'ya çıkıncaya kadar devam edilecek.

2.2.1.2. Eğer SVB $15 \mathrm{mmHg}$ olduğu halde arter basıncı düşük ise vazopresör infüzyonu başlanacak.

2.2.1.2.1. Noradrenalin ilk tercih $0,05 \mu \mathrm{g} / \mathrm{kg} / \mathrm{dk}$ ile başlanarak doz $2 \mu \mathrm{g} / \mathrm{kg} / \mathrm{dk}$ kadar 0,5 $\mu \mathrm{g}$ her 30 dakikada bir arttırılabilir.

2.2.1.2.2. Noradrenalin bulunamiyorsa Dopamin 5 $\mu \mathrm{g} / \mathrm{kg} / \mathrm{dk}$ ile başlanarak $20 \mu \mathrm{g} / \mathrm{kg} / \mathrm{dk}$ kadar $5 \mu \mathrm{g}$ aralıklarla her 30 dakikada bir arttırılabilir.

2.2.1.3. Santral ven kateterinden ölçülen $\mathrm{O} 2$ satürasyonu $\% 70$ 'in altındaysa

2.2.1.3.1. Hematokrit \%30 oluncaya kadar eritrosit süspansiyonu transfüzyonu uygulanacak (kan transfüzyonu protokolüne göre)

2.2.1.3.2. Dobutamin infüzyonu başlanacak $2,5 \mu \mathrm{g} / \mathrm{kg} / \mathrm{dk}$ ile başlanarak $20 \mu \mathrm{g} / \mathrm{kg} / \mathrm{dk}$ kadar 2,5 $\mu \mathrm{g}$ aralıklarla her 30 dakikada bir arttırılabilir.

2.2.1.4. Steroid başla

2.2.1.4.1. Ilk tercih hidrokortizondur. $300 \mathrm{mg} / \mathrm{gün} 100 \mathrm{~mL}$ serum fizyolojik içinde 24 saatlik infüzyon halinde 7 gün boyunca uygulanacak.

2.2.1.4.2. Eğer hidrokortizon bulunamazsa yerine metilprednizolon (Prednol L) $60 \mathrm{mg} / \mathrm{gün} 100 \mathrm{~mL}$ serum fizyolojik içinde 24 saatlik infüzyon halinde 7 gün boyunca uygulanacak.

2.3. Kan kültürü (1 adet santral kateterden 1 adet perifer veninden), idrar kültürü, entübe edilmişse ETA ve infeksiyon odağı düşünülen başka yerlerden örnek alınmaya çalışlacak. Alınan örnekler Infeksiyon Hastalıkları ve Klinik Mikrobiyoloji Anabilim Dalı laboratuarına gönderilecek.

2.4. Düşünülen kaynağa uygun olarak geniş spektrumlu antibiyotik başlanacak. (Antibiyotik seçimi için ünite uzman hekimlerine danışılacak).

2.5. Odak olabileceği düşünülen kateterler çıkartılacak

2.5.1. Giriş yerinde kızarıklık olan, giriş yerinden pü gelen kateterleri çıkartın ve kateter ucunu steril olarak keserek kültür için Infeksiyon Hastalıkları ve Klinik Mikrobiyoloji Anabilim Dalı laboratuarına gönderin.

2.5.2. Belirgin şekilde bulanık idrar, sondanın giriş yerinde akıntı gibi bulgular görürseniz mesane sondasını çıkartın ve yenisi ile değiştirin.

2.6. Olası bir odağı bulmak için gerekli görüntüleme girişimlerini yapın.

2.6.1. Her hastadan akciğer grafisi çekilecek.

2.6.2. Intraabdominal infeksiyon düşünülüyorsa

2.6.2.1. Karında distansiyon olup olmadığı kontrol edilecek, barsak seslerinin varlığı kontrol edilecek. Intraabdominal basınç ölçülecek.

2.6.2.2. Cerrahi konsültasyon istenecek

2.6.2.3. Batın ultrasonografi ve/veya batın bilgisayarlı tomografisi uygulanacak.
2.7. Mekanik ventilasyon

2.7.1. Hastada kontrendikasyonları yok ise 2 saat süre ile noninvazif mekanik ventilasyon denenebilir. 2 saat sonrasında kan gazlarında belirgin bir düzelme sağlanamıyorsa intübasyon ile mekanik ventilasyona devam edilmelidir.

2.7.1.1. Noninvazif mekanik ventilasyon kontrendikasyonları

2.7.1.1.1. Derin metabolik asidoz $(\mathrm{pH}<7.25)$

2.7.1.1.2. $\mathrm{PaO}_{2} / \mathrm{FiO}_{2}$ oranı $<20$

2.7.1.1.3. Şuurun kapalı olması (GKS $<10)$

2.7.1.1.4. Kardiyak arrest

2.7.1.1.5. Üst GIS kanaması

2.7.1.1.6. Septik şok

2.7.1.1.7. Yüzde deformite veya cerrahi girişim

2.7.1.1.8. Fazla miktarda sekresyon

2.7.2. Ağır sepsise bağlı ARDS tanısı varsa

2.7.2.1. $\mathrm{PaO}_{2} / \mathrm{FiO}_{2}$ oranı $>200$

2.7.2.2. Akut başlangıçlı solunum yetersizliği

2.7.2.3. Akciğer grafisinde bilateral infiltrasyon

2.7.2.4. Sol kalp yetersizliğinin klinik bulgularının bulunmaması veya pulmoner arter kateteri konmuş ise pulmoner arter uç basıncının (PKUB) 18 mmHg'dan düşük olması

2.7.3. ARDS'de mekanik ventilasyon

2.7.3.1. Orotrakeal intübasyon

2.7.3.2. Volüm kontrole ventilasyon

2.7.3.2.1. Tidal volüm $6 \mathrm{~mL} /$ tahmini vücut ağırlığı

2.7.3.2.2. Frekans $\mathrm{PaCO}_{2}$ düzeyine göre $12-18 / \mathrm{dk}$ arasında ayarlanacak (eğer ekspirasyon kısıtlanmıyorsa 20/dk'ya çıkabilir)

2.7.3.2.3. $\mathrm{FiO}_{2} \mathrm{SpO}_{2}>\% 90$ ve/veya $\mathrm{PaO}_{2}>60 \mathrm{mmHg}$ olacak şekilde ayarlanacak

2.7.3.2.4. Plato hava yolu basıncının $35 \mathrm{cmH}_{2} \mathrm{O}$ üzerine çıkmasına izin verilmeyecek

2.7.3.2.4.1. Yükselirse PRVC aynı parametrelerle uygulanabilir

2.7.3.2.4.2. Inspirasyon süresi $l: E$ oranı $2: 1^{\prime}$ den büyük olmayacak ve ekspirasyon akımı kısıtlanmayacak şekilde arttırlabilir.

2.7.3.3. Basınç kontrole ventilasyon

2.7.3.3.1. "Zirve" hava yolu basıncı $35 \mathrm{mmHg}$ aşmayacak şekilde üst basınç limiti ayarlanır.

2.7.3.3.2. Frekans $\mathrm{PaCO} 2$ düzeyine göre 12-18/dk arasında ayarlanacak (eğer ekspirasyon kısıtlanmıyorsa 20/dk'ya çıkabilir)

2.7.3.3.3. $\mathrm{FiO}_{2} \mathrm{SpO}_{2}>\% 90$ ve/veya $\mathrm{PaO}_{2}>60 \mathrm{mmHg}$ olacak şekilde ayarlanacak

2.7.3.3.4. Eğer tidal volüm $<6 \mathrm{~mL} / \mathrm{kg}$ kalırsa Inspirasyon süresi I:E oranı 2:1'den büyük olmayacak ve ekspirasyon akımı kısıtlanmayacak şekilde arttırılabilir.

2.7.3.4. Rekruitment manevras।

2.7.3.4.1. Hastalara ARDS tanısı konduğunda rekruitment manevrası uygulaması esastır. 
2.7.3.4.2. Rekruitment manevrası $\mathrm{FiO}_{2} 1.0$ 'a çıkartıldıktan sonra bir kez 40-45 saniye süreyle 40-45 cmH2O CPAP uygulanarak yapilır. (Bu uygulama sırasında hastanın ventilatörü tetiklemesi ve PSV uygulanması engellenmelidir.)

2.7.3.4.3. Rekruitment manevrası her endotrakeal aspirasyon ve hastanın ventilatörden ayrımasından sonra ve/veya kan gazlarında bozulma olduğunda tekrarlanmalıdır.

2.7.3.5. PEEP düzeyinin ayarlanması

2.7.3.5.1. Rekruitment manevrası uygulamasının bitmesi ile ventilatör ayarları başlangıç ayarlarına döndürülür.

2.7.3.5.2. PEEP düzeyi $18 \mathrm{cmH}_{2} \mathrm{O}$ ayarlanır ve 10 dakika sonra $\mathrm{PaO}_{2}$ kaydedilir. Sonra PEEP düzeyi her 10 dakikada bir $\mathrm{PaO}_{2}$ kaydedilmek üzere $2 \mathrm{cmH}_{2} \mathrm{O}$ azaltılır.

2.7.3.5.3. $\mathrm{PaO} 2$ 'nin aşırı düzeyde (bir öncekine göre $>\% 20$ ) düştüğü PEEP düzeyi tespit edilir ve yeni bir rekruitment manevrasının ardından bu düzeyin $2 \mathrm{cmH} 2 \mathrm{O}$ üstünde ayarlanarak bıraklır. Eğer $\mathrm{PaO}_{2}$ 'de belirgin düşüş tespit edilemezse PEEP $8 \mathrm{cmH} 2 \mathrm{O}^{\prime}$ ya kadar düşürülerek burada bırakılır (2. kez rekruitment gerekmez)

2.7.3.6. $\mathrm{PaCO}_{2}$ düzeyinin yükselmesine izin verilir ancak pH'ın 7.3'ün altına düşmesi halinde ve hemodinamik bozukluklar oluşuyorsa bikarbonat tedavisi başlanması düşünülebilir.

2.7.4. Mekanik ventilasyon uygulanan tüm hastalar eğer dolaşım şoku yok ise başları 35o yukarıda kalacak şekilde yatırımalıdırlar.

2.8. Kan şekeri kontrolü

2.8.1. Kan şekeri düzeyi $150 \mathrm{mg} / \mathrm{dL}$ altında tutulmalıdır.

\begin{tabular}{|c|c|c|}
\hline & $\begin{array}{l}\text { Şeker düzeyi } \\
\text { (mg/dL) }\end{array}$ & $\begin{array}{l}\text { İnsülin Dozu } \\
\text { (Ü/saat) }\end{array}$ \\
\hline \multirow[t]{3}{*}{$\begin{array}{l}\text { YBÜ girişinde } \\
\text { ve takip sırasında }\end{array}$} & $>220$ & $2-4$ \\
\hline & $220-110$ & $1-2$ \\
\hline & $<110$ & $\begin{array}{c}\text { Başlama, her } \\
4 \text { saatte bir } \\
\text { KŞ düzeyi ölçümü }\end{array}$ \\
\hline \multirow[t]{5}{*}{$\begin{array}{l}\text { Kan şekeri yatış süresince } \\
4 \text { saatte bir izlenir }\end{array}$} & $80-110$ & $0,1-0,5$ \\
\hline & Hızla düşüyor & $\begin{array}{l}\text { Dozu yarıya in ve } \\
30 \text { dk'da bir kan } \\
\text { şekeri bak }\end{array}$ \\
\hline & $60-80$ & $\begin{array}{c}\text { Infüzyonu kes } \\
1 \text { saatte bir } \\
\text { kan şekeri bak }\end{array}$ \\
\hline & $40-60$ & $\begin{array}{l}\text { Infüzyonu kes, } \\
\text { yeterli miktarda glukoz } \\
\text { aldığına emin ol ve } \\
30 \text { dk'da bir kan } \\
\text { şekeri bak }\end{array}$ \\
\hline & $<40$ & $\begin{array}{c}\text { İnfüzyonu kes, } \\
\text { yeterli miktarda } \\
\text { glukoz aldığına } \\
\text { emin ol, } 10 \mathrm{~g} \text { IV glukoz } \\
\text { ver ve } 30 \mathrm{dk} \text { 'da bir } \\
\text { kan şekeri bak }\end{array}$ \\
\hline
\end{tabular}

2.9. Drotrekogin Alfa (Xigris tedavisi)

2.9.1. Uygun hastalarda tanıyı takip eden ilk 48 saat içinde infüzyona başlanması esastır.

2.9.1.1. Ağır sepsis tanısı

2.9.1.2. 2 ve daha fazla organ yetersizliği

2.9.1.3. Kontrendikasyonlarının bulunmaması

2.9.1.3.1. Intrakraniyal hemoraji, tümör veya herniyasyon bulguları

2.9.1.3.2. $\geq 15 \mathrm{IU} / \mathrm{kg} / \mathrm{saat}$ heparin infüzyonu

2.9.1.3.3. Sepsise bağlı koagülopati dışında bilinen kanama eğilimi

2.9.1.3.4. Trombosit sayısI $<30.000 / \mathrm{mm}^{3}$

2.9.1.3.5. Kanama riski yüksek olan hastalar (epidural kateteri olan hastalar)

2.9.2. Xigris $24 \mu \mathrm{g} / \mathrm{kg} / \mathrm{saat}$ devamlı infüzyon şeklinde 96 saat süresince uygulanır.

2.9.3. Xigris uygulaması süresince hastalar kanama yönünden izlenmelidir.

2.9.4. Eğer hastaya invazif girişim uygulanacaksa Xigris girişimden 2 saat önce kesilmelidir. Tekrar başlamak için

2.9.4.1. Minör girişimler (arter kanülü, femoral ven kateteri, entübasyon) girişim sonrası infüzyon hemen başlanabilir.

2.9.4.2. Daha invazif girişimler (santral ven kateterizasyonu, toraks dreni, lomber ponksiyon vb) iki saat kanama olup olmadığı izlenir yoksa infüzyon tekrar başlanır

2.9.4.3. Laparotomi, torakotomi gibi operasyonlar sonrası infüzyona başlamak için 12 saat beklenmelidir.

2.9.4.4. Infüzyon tekrar aynı hızla 96 saat tamamlanıncaya kadar verilir.

2.10. Sedasyon

2.10.1. Sedasyon düzeyi Ramsay skalasında 3-4 düzeyinde tutulacak şekilde ayarlanır, eğer hastaya akciğer koruyucu ventilasyon stratejisi uygulanıyorsa 5-6'ya kadar derinleştirmek gerekli olabilir.

\begin{tabular}{ll}
\hline Hasta uyanık, ajite & 1. Düzey \\
Hasta uyanık, sakin ve koopere & 2. Düzey \\
Hasta uyuyor fakat sesli uyaranla göz açıyor & 3. Düzey \\
Uyuyor, yüksek sesli uyaran veya ağıılı & \\
uyaranla gözünü açıyor & 4. Düzey \\
Uyuyor şiddetli ağılı uyarana yanıt veriyor & 5. Düzey \\
Uyaranlara hiç yanıt vermiyor & 6. Düzey
\end{tabular}

2.10.2. Sedasyon için Midazolam ve Morfin (şoktaki hastalarda Fentanil) infüzyonları ile sağlanır.

2.10.2.1. Midazolam başlangıç dozu bolus $2.5 \mathrm{mg}$ sonra $2-10 \mathrm{mg} / \mathrm{saat}$

2.10.2.2. Morfin başlangıç dozu 1-10 mg/saat

2.10.2.3. Fentanil 50-100 $\mu \mathrm{g}$ bolus sonrası $100-200$ $\mu \mathrm{g} / \mathrm{saat}$ infüzyon

2.10.3. Yoğun bakım hastalarında nöromüsküler bloker kullanımı tercih edilmez, ancak ARDS hastalarında düşük tidal volüm uygulaması nedeniyle solunum eforunun artması ve ventilatör ile uyumsuzluk, hava yolu basınçlarının artması ve gaz değişiminin bozulması söz konusu ise Vekuronyum $4 \mathrm{mg}$ IV bolus lüzumu halinde kullanııır (infüzyondan kaçınılmalıdır) 


\section{Ek 2: Ağır Sepsis Takip Formu:}

Tarih:

\begin{tabular}{|c|c|c|c|c|}
\hline $\begin{array}{l}\text { Protokol No: } \\
\text { Apache II: }\end{array}$ & $\begin{array}{l}\text { Defter No: } \\
\text { SOFA: }\end{array}$ & Yaş: & & Cins: \\
\hline Hasta Ağır Sepsis mi? & Evet & $\square$ & Hayır & $\square$ \\
\hline Hasta Septik Şok mu? & Evet & $\square$ & Hayır & $\square$ \\
\hline Sepsis Odağı? & iğer & abdominal & Üriner & Diğer \\
\hline \multicolumn{2}{|c|}{ Hastada immünsupresyon var mı? } & Evet $\square$ & & Hayır $\square$ \\
\hline
\end{tabular}

\section{Sepsis Tanısı ne zaman kondu?}

YBÜ yatış zamanı :

Tarih (gün/ay/yıl) _ _ _ _ _ _ saat (24 saat): __ _ _ _

Tarih (gün/ay/yıl) _ _ _ _ _ saat (24 saat): __ / _ _

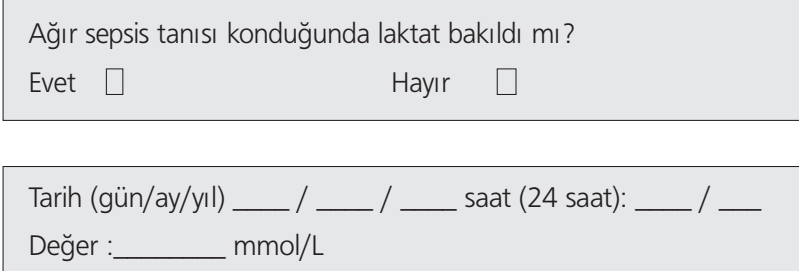

Ağır sepsis tanısı konduğunda hemokültür alındı mı?

Evet $\square$

Hayır $\square$

\begin{abstract}
Ağır sepsis tanısı konduğunda geniş spektrumlu antibiyotik başlandı mı? (Acilden gelenlerde 180 dakika, servisten gelenlerde 60 dakika içinde)

Evet $\square$ Hayır $\square$

Antibiyotik(ler) :

Tarih (gün/ay/yıl) __ / _ _ _ _ _ saat (24 saat): __ _ _ _
\end{abstract}

Sistolik $A B<90 \mathrm{mmHg}$, Ortalama $A B<65 \mathrm{mmHg}$ veya Laktat $>4 \mathrm{mmol} /$ L'mi? $^{\prime}$

Evet $\square$

Hayır $\square$

Sıvı replasmanı: >20 ml/kg kristalloid veya eşdeğer kolloid başlandı mı?
Evet $\square$
Hayır
Gerek yok

Arter basıncı sıvı replasmanına cevap verdi mi?
Evet $\square \quad$ Hayır $\square$

Hayır $\square$

CVP 8-12 arası oldu mu?

Evet $\square$

Hayır $\square$

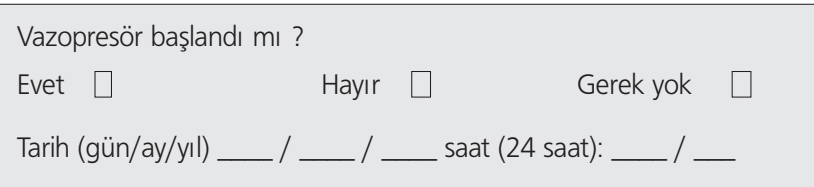

ScvO2 \%70'in altında mı?

Evet $\square$ Hayır

Dobutamin başlandı mı?

Evet $\square \quad$ Hayır $\quad \square \quad$ Gerek yok $\quad \square$

Hematokrit $<\% 30$ 'mu

Evet $\square \quad$ Hayır $\square$

Eritrosit transfüzyonu yapıldı mı?

Evet $\square \quad$ Hayır $\quad \square \quad$ Gerek yok $\square$

ScvO2 tanıdan sonra 6 saat içinde $>\% 70$ oldu mu?

Evet $\square \quad$ Hayır $\quad \square \quad$ Gerek yok $\square$

Düşük doz steroid başlandı mı?

Evet $\square \quad$ Hayır $\quad \square \quad$ Gerek yok $\square$

illaç : $\quad$ Hidrokortizon $\quad \square \quad$ Metilprednizolon

Tarih (gün/ay/yıl) __ _ _ _ _ _ saat (24 saat): __ _ _ _

Ağır sepsis tanısından sonra 24 saat içinde drotrekogin alfa başlandı mı? Evet Hayır $\square \quad$ Gerek yok Kontrendikasyon $\square \quad$ illaç yok $\square$

Daha uzun bir süre içinde Drotrecogin Alfa başlandımı?

$\begin{array}{lll}\text { Evet } \square & \text { Hayır } \square & \text { Gerek yok } \square \\ \text { Kontrendikasyon } \square & \text { illaç yok } \quad \square & \end{array}$

Illk 24 saat içinde medyan kan şekeri düzeyi <150 mg/dl mi? Evet $\square \quad$ Hayır $\square$

illk 24 saat içinde en düşük kan şekeri düzeyi : $\mathrm{mg} / \mathrm{dl}$

Illk 24 saat içinde ortanca plato basınc (volüm kontrole) veya zirve basınç (basınç kontrole) $<30 \mathrm{cmH} 22 \mathrm{mu}$ ?

Evet Hayır $\square \quad$ Gerek yok

Hastanın çıkış durumu:

Çıkış Tarih (gün/ay/yıl) __ l _ _ _ _ saat (24 saat): ___ _ _ 


\section{Kaynaklar}

1. Bone RC, Balk RA, Cerra FB, Dellinger RP, Fein AM, Knaus WA, Schein RMH, Sibbald WJ. Definitions for sepsis and organ failure and guidelines for the use of innovative therapies in sepsis. Chest 1992;101:1644-55.

2. Martin GS, Mannino DM, Eaton S, Moss M. The epidemiology of sepsis in the United States from 1979 through 2000. N Engl J Med 2003;348:1546-54.

3. Rangel-Frausto MS, Pittet D, Hwang T, Woolson RF, Wenzel RP. The dynamics of disease progression in sepsis: Markov modeling describing the natural history and the likely impact of effective antisepsis agents. Clin Infect Dis 1998;27:185-90.

4. Margaux Conference on Sepsis and Coagulation. 2000. Crit Care Med 28:S1-S89.

5. Friedman G, Silva E, Vincent JL. Has the mortality of septic shock changed with time. Crit Care Med 1998;26:2078-86.

6. Bodur HA, Koca U. Ağır sepsiste mortaliteyi etkileyen faktörler. TARK 2005 Antalya.

7. Çopuroğlu E, Bilgili B. Ve ark. Ağır sepsiste organ yetersizliklerinin mortaliteye etkisi. TARK 2006 Antalya.

8 Rivers E, Nguyen B, Havstad S, Ressler J, Muzzin A, Knoblich B, et al. Early goal-directed therapy in the treatment of severe sepsis and septic shock. N Engl J Med 2001;345:1368-77.

9. Bernard GR, Vincent JL, Laterre PF, LaRosa SP, Dhainaut JF, Lopez-Rodriguez A, et al. Efficacy and safety of recombinant human activated protein $\mathrm{C}$ for severe sepsis. New Engl J Med 2001;344:699-709.

10. Annane D, Sebille V, Charpentier C, Bollaert PE, Francois B, Korach JM, et al. Effect of treatment with low doses of hydrocortisone and fludrocortisone on mortality in patients with septic shock. JAMA 2002;288:862-71.

11. Van den Berghe G, Wouters P, Weekers F, Verwaest C, Bruyninckx F, Schetz $M$, et al. Intensive insulin therapy in the critically ill patients. N Engl J Med 2001;345:1359-67.

12. Ventilation with lower tidal volumes as compared with traditional tidal volumes for acute lung injury and the acute respiratory distress syndrome. The Acute Respiratory Distress Syndrome Network. N Engl J Med 2000;342:1301-8.

13. Nguyen HB, Corbett SW, Steele R, Banta J, Clark RT, Hayes SR, et al. Implementation of a bundle of quality indicators for the early management of severe sepsis and septic shock is associated with decreased mortality. Crit Care Med 2007;35:1105-12.

14. Brun-Buisson. Anonymus: Summary of recommendations. Intensive Care Med 2001, 27:S128-S134.

15. Kieft H, Hoepelman Al, Zhou W, Rozenberg-Arska M, Struyvenberg A, Verhoef $\mathrm{J}$. The sepsis syndrome in a Dutch university hospital. Clinical observations. Arch Intern Med 1993;153:2241-7.

16. Russell JA, Singer J, Bernard GR, Wheeler A, Fulkerson W, et al. Changing pattern of organ dysfunction in early human sepsis is related to mortality. Crit Care Med 2000;28:3405-11.

17. Umegaki T, Ikai $H$, Imanaka $Y$. The impact of acute organ dysfunction on patients mortality with severe sepsis. J Anaesthesiol Clin Pharmacol 2011;27:180-4.

18. Annane D, Aegerter P, Jars-Guincestre MC, Guidet B; CUB-Rea Network. Current epidemiology of septic shock: the CUB-Réa Network. Am J Respir Crit Care Med 2003;168:165-72.

19. Carson SS, Stocking C, Podsadecki T, Christenson J, Pohlman A, MacRae S, et al. Effects of organizational change in the medical intensive care unit of a teaching hospital: a comparison of 'open' and 'closed' formats. JAMA 1996;276:322-8.
20. Poeze M, Ramsay G, Gerlach H, Rubulotta F, Levy M. An international sepsis survey: a study of doctors' knowledge and perception about sepsis. Crit Care 2004;8(6):R409-13.

21. Blow O, Magliore L, Claridge JA, Butler K, Young JS. The golden hour and the silver day: Detection and correction of occult hypoperfusion within 24 hours improves outcome from major trauma. J Trauma 1999;47:964-9.

22. Boersma E, Maas AC, Deckers JW, Simoons ML. Early thrombolytic treatment in acute myocardial infarction: Reappraisal of the golden hour. Lancet 1996;348:771-5.

23. Wood KE. Major pulmonary embolism: Review of a pathophysiologic approach to the golden hour of hemodynamically significant pulmonary embolism. Chest 2002;121:877-905.

24. Field MJ, Lohr KN. Guidelines for clinical practice: from development to use. Washington, DC: National Academy Pres, 1992.

25. Woolf SH, Grol R, Hutchinson A, Eccles M, Grimshaw J. Clinical guidelines: potential benefits, limitations, and harms of clinical guidelines. BMJ 1999;318;527-30.

26. Kuperman GJ, Boyle D, Jha A, Rittenberg E, Ma'Luf N, Tanasijevic MJ, et al. How promptly are inpatients treated for critical laboratory results? J Am Med Inform Assoc 1998;5:112-9.

27. Wennberg JE. Understanding geographic variations in health care delivery. N Engl J Med 1999;340:52-3.

28. Trzeciak S, Dellinger RP, Abate NL, Cowan RM, Stauss M, Kilgannon JH, et al. Translating research to clinical practice: a 1year experience with implementing early goal-directed therapy for septic shock in the emergency department. Chest 2006;129:225-32.

29. Micek ST, Roubinian N, Heuring T, Bode M, Williams J, Harrison C, et al. Before-after study of a standardized hospital order set fort he management of septic shock. Crit Care Med 2006;34:2707-13.

30. Shapiro NI, Howell MD, Talmor D, Lahey D, Ngo L, Buras J, et al. Implementation and outcomes of the Multiple Urgent Sepsis Therapies (MUST) protocol. Crit Care Med 2006;34:1025-32.

31. Kortgen A, Niederprum $P$, Bauer M. Implementation of an evidence-based Standard operating procedure and outcome in septic shock. Crit Care Med 2006;34:943-9.

32. Groeger JS, Guntupalli KK, Strosberg M, Halpern N, Raphaely $\mathrm{RC}$, Cerra F, et al. Descriptive analysis of critical care units in the United States: patient characteristics and intensive care unit utilization. Crit Care Med 1993;21:279-91.

33. Gao F, Melody T, Daniels DF, Giles S, Fox S. The impact of compliance with 6-hour and 24-hour sepsis bundles on hospital mortality in patients with severe sepsis: a prospective observational study. Crit Care 2005;9:653-4.

34. Morrell M, Fraser VJ, Kollef MH. Delaying the empiric treatment of candida blood stream infection until positive blood culture results are obtained: A potential risk factor for hospital mortality. Antimicrob Agents Chemother 2005;49:3640-5.

35. Institude of Medicine: Crossing the Quality Chasm: A New Health System fort he 21st century. Washington, DC: National Academy Pres; 2001.

36. Levy MM, Dellinger RP, Townsend SR, Linde-Zwirble WT, Marshall JC, Bion J, et al The Surviving Sepsis Campaign: Results of an international guideline-based performance improvement program Targeting severe sepsis. Crit Care Med 2010;38:367-74.

37. Miguel-Yanes JM, Andueza-Lillo JA, Gonzalez-Ramallo VJ, Pastor L, Munoz J. Failure to implement evidence-based clinical guidelines for sepsis at the ED. Am J Emerg Med 2006;24:553-9. 